
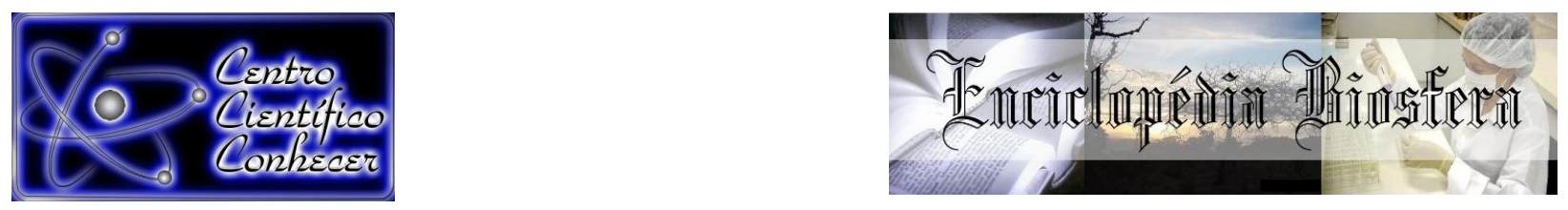

\title{
DIVERSIDADE CULTURAL DE CEPAS DE ACTINOBACTÉRIAS DO SEMIÁRIDO
}

Elizabeth Jordanya Teixeira Medeiros ${ }^{1}$, Fernando Gouveia Cavalcante ${ }^{2}$, Valéria Maria Araújo Silva ${ }^{3}$, Suzana Cláudia Silveira $^{4}$, Claudia Miranda Martins $^{5}$

1. Graduada na Universidade Federal do Ceará-Campus do Pici, Fortaleza-CE, Brasil. lizzie27.bio@gmail.com

2. Doutorando do Programa de Pós-graduação em Ecologia e Recursos Naturais na Universidade Federal do Ceará-Campus do Pici, Fortaleza-CE, Brasil.

3. Doutoranda do Programa de Pós-graduação em Ecologia e Recursos Naturais na Universidade Federal do Ceará-Campus do Pici, Fortaleza-CE, Brasil.

4. Docente na Universidade Federal do Ceará-Campus do Pici, Fortaleza-CE, Brasil.

5. Docente na Universidade Federal do Ceará-Campus do Pici, Fortaleza-CE, Brasil claudia.miranda.martins@gmail.com

Recebido em: 06/04/2018 - Aprovado em: 10/06/2018 - Publicado em: 20/06/2018 DOI: 10.18677/EnciBio_2018A87

\begin{abstract}
RESUMO
As actinobactérias são os principais constituintes da comunidade microbiana do solo, correspondendo cerca de $77 \%$ dos micro-organismos totais. Tendo em vista a grande diversidade de actinobactérias na região semiárida a caracterização cultural torna-se uma ferramenta de suma relevância na classificação e identificação desses organismos. O registro da diversidade cultural através de imagens pode contribuir nos estudos desse grupo. Dessa forma, o objetivo do trabalho foi a caracterização cultural e registro fotográfico de 37 cepas de actinobactérias oriundas de Quixeramobim (CE), região do semiárido nordestino. Como plano de fundo, no registro das cepas, foram utilizadas as cores branca e preta, dependendo da coloração do micélio. Foi realizado o registro fotográfico de cada colônia, indicando, em uma avaliação por critério de similaridade, que as actinobactérias são subdivididas em 23 grupos distintos.
\end{abstract}

PALAVRAS-CHAVE: caatinga, Streptomyces, micro-organismos do solo 


\begin{abstract}
Actinobacteria are the main constituents of the soil microbial community, corresponding to about $77 \%$ of soil microbiota. Considering the great diversity of actinobacteria in the semi-arid region, cultural characterization acts as a relevant tool in the classification and identification of these organisms. The registration of cultural diversity through images can contribute to the studies of this group. Thus, the objective of the study was the cultural characterization and photographic record of 37 strains of actinobacteria from Quixeramobim (CE) region of the northeastern semi arid region. As background, in the record of the strains, the colors white and black were used, depending on the color of the mycelium. The photographic record of each colony was carried out, indicating, in an evaluation by similarity criterion, that the actinobacteria are subdivided into 23 distinct groups.
\end{abstract}

KEY WORDS: caatinga, Streptomyces, soil microorganisms

\title{
INTRODUÇÃO
}

O semiárido nordestino apresenta condições abióticas restritivas, altas taxas de insolação, temperaturas elevadas, baixas amplitudes térmicas, baixas taxas pluviométricas e apresentam alta variabilidade no tempo e no espaço, ocorrendo ainda, elevadas taxas de evapotranspiração e déficit hídrico acrescido (ZANELLA, 2014). O solo dessa região possui hábitats bem próprios e característicos, sendo bastante rico e ainda pouco conhecido e explorado. Vegetação diversificada, elevada temperatura e baixa umidade do solo são predominantes nessa região (KAVAMURA et al., 2013).

Mesmo com essas condições estressantes presentes na região semiárida, e apesar dessas condições limitarem o crescimento de populações bacterianas, alguns micro-organismos, como as actinobactérias compõem um grupo significativo em se tratando de riqueza e diversidade nos solos do bioma caatinga (LIMA et al., 2014; SILVA et al., 2015). As actinobactérias estão, portanto, presentes em abundância e de forma bastante diversificada (BRITO et al., 2015; SILVA et al., 2015).

São os micro-organismos mais encontrados no solo, dentre todos os outros, e estão distribuídos em larga escala, sendo abundantes, sobretudo na rizosfera (STROBEL et al., 2004; BHASIN et al., 2010). Uma característica típica desse grupo é o fato de produzirem o composto geosmina que apresenta odor típico de terra molhada (MOREIRA et al., 2006).

O filo Actinobacteria pertence a um grupo diferenciado de bactérias, o qual está extensamente disseminado na natureza (SEMÊDO et al., 2001; SILVA et al., 2013). Esse filo apresenta uma grande diferenciação morfológica entre as bactérias Gram-positivas, entretanto, vale ressaltar que a estrutura celular de actinobactéria é semelhante à de qualquer procarioto, sendo, portanto, totalmente divergente da estrutura fúngica (BARKA et al., 2015; LI et al., 2016;).

Produzem compostos bioativos que apresentam atividade antimicrobiana contra diversos patógenos inclusive os resistentes a diversos medicamentos (SERVIN et al., 2008; BALLAV et al., 2012) e, além disso, têm provado sua importância no mercado enzimático (BHASIN et al., 2010). O gênero Streptomyces, especialmente, são produtores prolíficos de metabólitos secundários, utilizados como agentes de biocontrole, responsáveis por restringir o crescimento de fitopatógenos (PRIYADHARSINI; DHANASEKARAN, 2015). 
Em ambientes terrestres, as enzimas produzidas por actinobactérias estão envolvidas na mineralização de nutrientes e em processos de decomposição de moléculas orgânicas que se apresentam resistentes, inclusive substâncias húmicas (GORLACH-LIRA; COUTINHO, 2007; LIMA et al., 2014). A capacidade de degradação que as actinobactérias possuem é de extrema importância para o ciclo do carbono e formação de húmus no solo, o qual beneficia a disponibilidade de nutrientes para o desenvolvimento da planta (BRITO et al., 2015).

Em actinobactérias típicas, o micélio pode ser dividido em micélio aéreo e reverso. Algumas cepas podem formar estruturas complexas como esporo, cadeia de esporo, esporângio e esporangiósporo; o crescimento e modos de ruptura do micélio reverso, a posição do esporo, o número de esporo, a estrutura superficial deste, o molde do esporângio, e se o esporangiósporo possui flagelo ou não, são características morfológicas importantes para classificação de actinobactérias (LI et al., 2016).

Tendo em vista a grande diversidade de actinobactérias na região semiárida, o registro da diversidade cultural através de imagens, irá contribuir nos estudos desse grupo, dessa forma o objetivo do trabalho foi a caracterização cultural e a criação de acervo fotográfico de cepas de actinobactérias do semiárido.

\section{Área de estudo}

\section{MATERIAL E MÉTODOS}

Foram utilizados nesse estudo cepas de actinobactérias provenientes de solo da região de Quixeramobim, cidade do Estado do Ceará, localizado na Mesorregião dos Sertões Cearenses, especificamente na Fazenda Normal, que está compreendida entre a latitude $5^{\circ} 07^{\prime} 12,1^{\prime \prime}$ S e a longitude $39^{\circ} 10^{\prime} 33,3^{\prime \prime}$ W. O clima é classificado como Tropical Quente Semiárido, pluviosidade média anual de 600,1 a $800 \mathrm{~mm}$, e concentrada nos meses de fevereiro e abril e a temperatura média é de $26{ }^{\circ} \mathrm{C}$ a $42{ }^{\circ} \mathrm{C}$ (IPECE, 2014).

\section{Actinobactérias}

Foram selecionadas 37 cepas a partir das 194 isoladas do solo de Quixeramobim, tendo como principal requisito a diversidade quanto ao aspecto cultural. As cepas foram previamente codificadas como "QB", indicativo de Quixeramobim, seguido pelo número.

As cepas de actinobactérias selecionadas foram: QB-03, QB-12, QB-14, QB17, QB-23, QB-29, QB-32, QB-39, QB-52, QB-60, QB-64, QB-70, QB-72, QB-76, QB-81, QB-90, QB-93, QB-99, QB-100, QB-102, QB-104, QB-114, QB-115, QB-116, QB-117, QB-118, QB-127, QB-132, QB-139, QB-148, QB-152, QB-157, QB-174, QB-182, QB-183, QB-192, QB-194. Essas cepas são mantidas em tubos com meio caseína dextrose (CD), a $25^{\circ} \mathrm{C}$ no Laboratório de Microbiologia Ambiental (LAMAB) do Departamento de Biologia da Universidade Federal do Ceará, compondo a Coleção de Cultura de Actinobactérias do Semiárido.

\section{Cultivo das cepas}

As cepas selecionadas foram inoculadas em meio CDA (em placa de Petri), com a seguinte composição para $1000 \mathrm{~mL}$ : 0,5 g de $\mathrm{K}_{2} \mathrm{HPO}_{4}$ (fosfato de potássio), 
0,2 $\mathrm{g}$ de $\mathrm{MgSO}_{4} .7 \mathrm{H}_{2} \mathrm{O}$ (sulfato de magnésio), $2 \mathrm{~g}$ de glicose, 0,01g de $\mathrm{FeSO}_{4} .7 \mathrm{H}_{2} \mathrm{O}$ (sulfato de ferro), 0,2 g de caseína (previamente dissolvida em $10 \mathrm{~mL}$ de $\mathrm{NaOH}$ 0,1 $\mathrm{N}$ ), $15 \mathrm{~g}$ de ágar, $10 \mathrm{~mL} \mathrm{NaOH}$ e 2,5 mL de nistatina (antifúngico). $\mathrm{O} \mathrm{pH}$ foi ajustado para $6,5 \sim 6,6$.

Além da inoculação em placa de Petri, houve ainda, a inoculação em caldo $\mathrm{CD}$ (em tubo de ensaio), cuja composição para $500 \mathrm{~mL}$ deste consiste em: $0,25 \mathrm{~g}$ de $\mathrm{K}_{2} \mathrm{HPO}_{4}$ (fosfato de potássio), 0,1 g de $\mathrm{MgSO}_{4} .7 \mathrm{H}_{2} \mathrm{O}$ (sulfato de magnésio), $1 \mathrm{~g}$ de glicose, 0,005 g de $\mathrm{FeSO}_{4} .7 \mathrm{H}_{2} \mathrm{O}$ (sulfato de ferro), 0,1 $\mathrm{g}$ de caseína (previamente dissolvida previamente em $5 \mathrm{ml}$ de $\mathrm{NaOH} 0,1 \mathrm{~N}), 10 \mathrm{~mL} \mathrm{NaOH}(0,4 \mathrm{~g}$ de $\mathrm{NaOH}$ para $100 \mathrm{~mL}$ de água, sendo que apenas $5 \mathrm{~mL}$ foi utilizado). $\mathrm{O} \mathrm{pH}$ foi ajustado para 6,5 6,6. As placas foram incubadas em B.O.D. a $28{ }^{\circ} \mathrm{C}$ por 14 dias. Após esse período foi realizado o registro fotográfico.

Foi realizada ainda, outra inoculação com o objetivo de obter colônias com diâmetro maior para facilitar o registro por meio de foto. Para isso, uma alíquota de $10 \mu \mathrm{L}$ do caldo CD, previamente agitado em vórtex, foi inoculado no centro da placa. As placas foram incubadas em B.O.D. a $28^{\circ} \mathrm{C}$ por 14 dias, em seguida, realizou-se o registro fotográfico.

\section{Caraterização cultural}

Para descrição das características culturais foram avaliadas as cores do micélio aéreo e reverso das colônias, conforme descrito por WINK (2012), baseada na carta de cores (RAL color charts).

\section{Registro fotográfico}

As fotos foram realizadas com as placas abertas em câmara de fluxo laminar, para dar um melhor contraste, os planos de fundo foram branco e preto, alternadamente. As fotografias das cepas foram captadas em planos superior, inferior e horizontal, para uma melhor visualização, enquanto, que para as colônias isoladas foram escolhidos apenas os planos superior e inferior.

\section{RESULTADOS E DISCUSSÃO}

A diversidade cultural das cepas oriundas de Quixeramobim, pode ser observada pelo registro fotográfico, que abrange imagens das placas de Petri com enfoque no micélio aéreo e no micélio reverso (Figura 1), no plano horizontal (Figura 2) e colônias isoladas (Figura 3). 


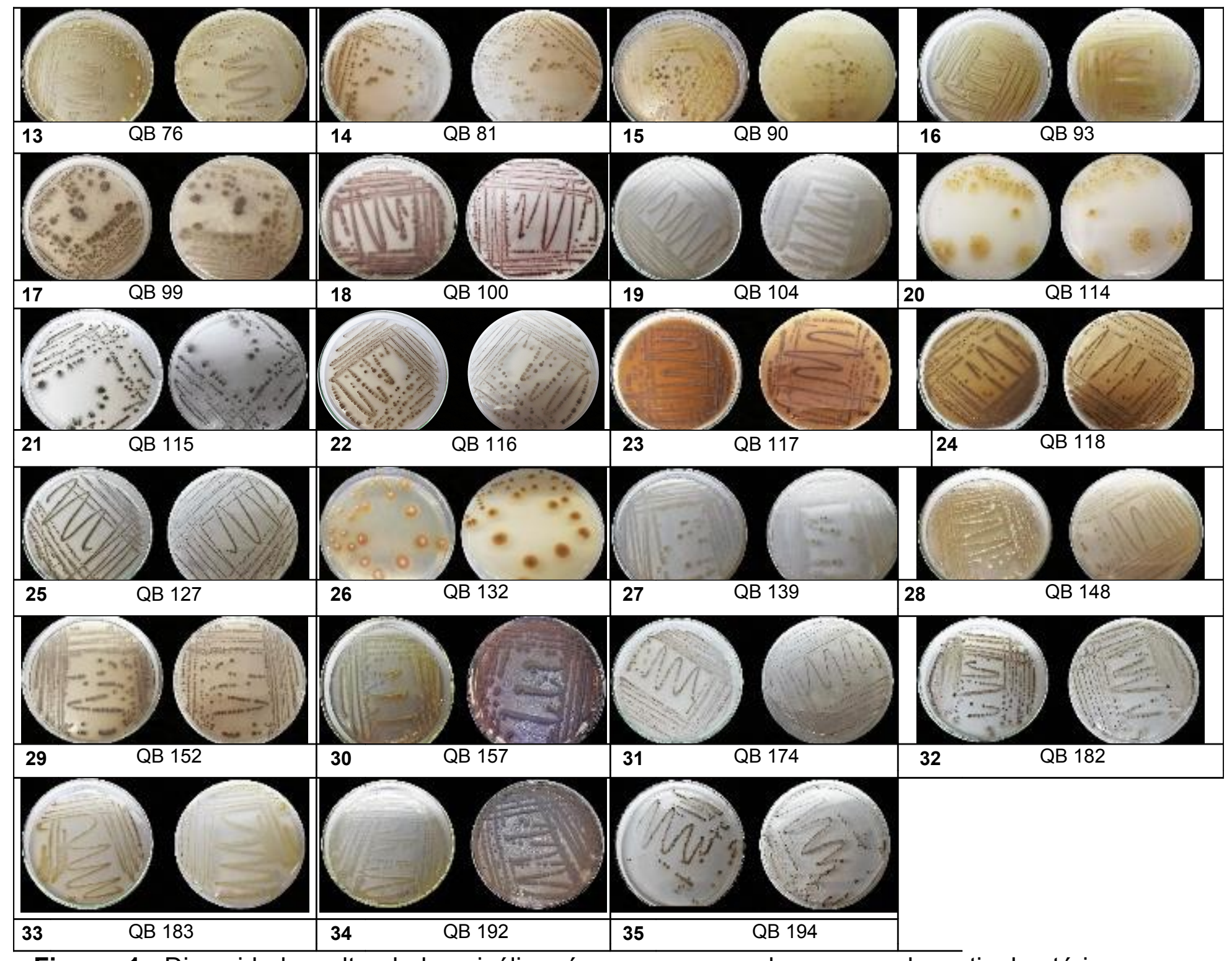

Figura 1: Diversidade cultural do micélio aéreo e reverso das cepas de actinobactérias oriundas de Quixeramobim (Ce). 


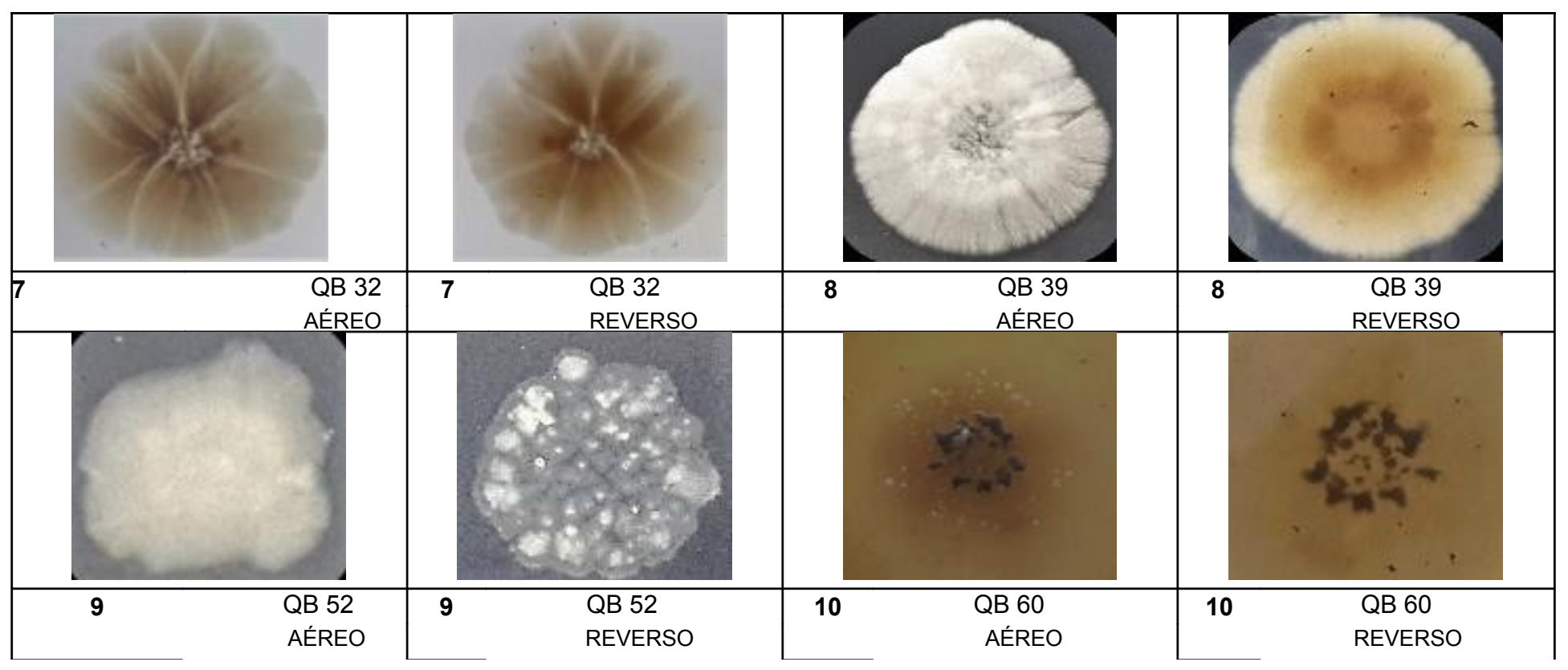




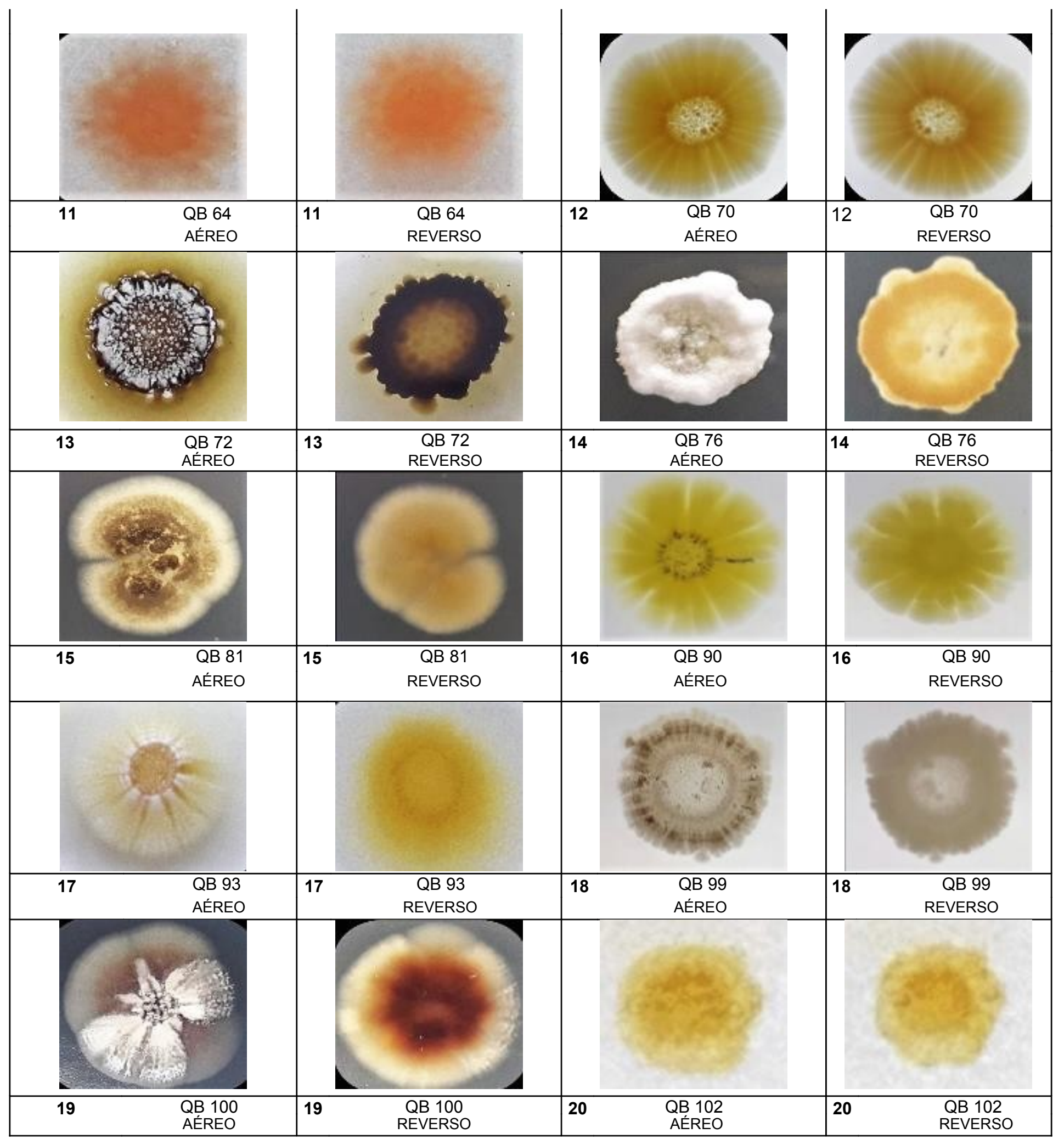




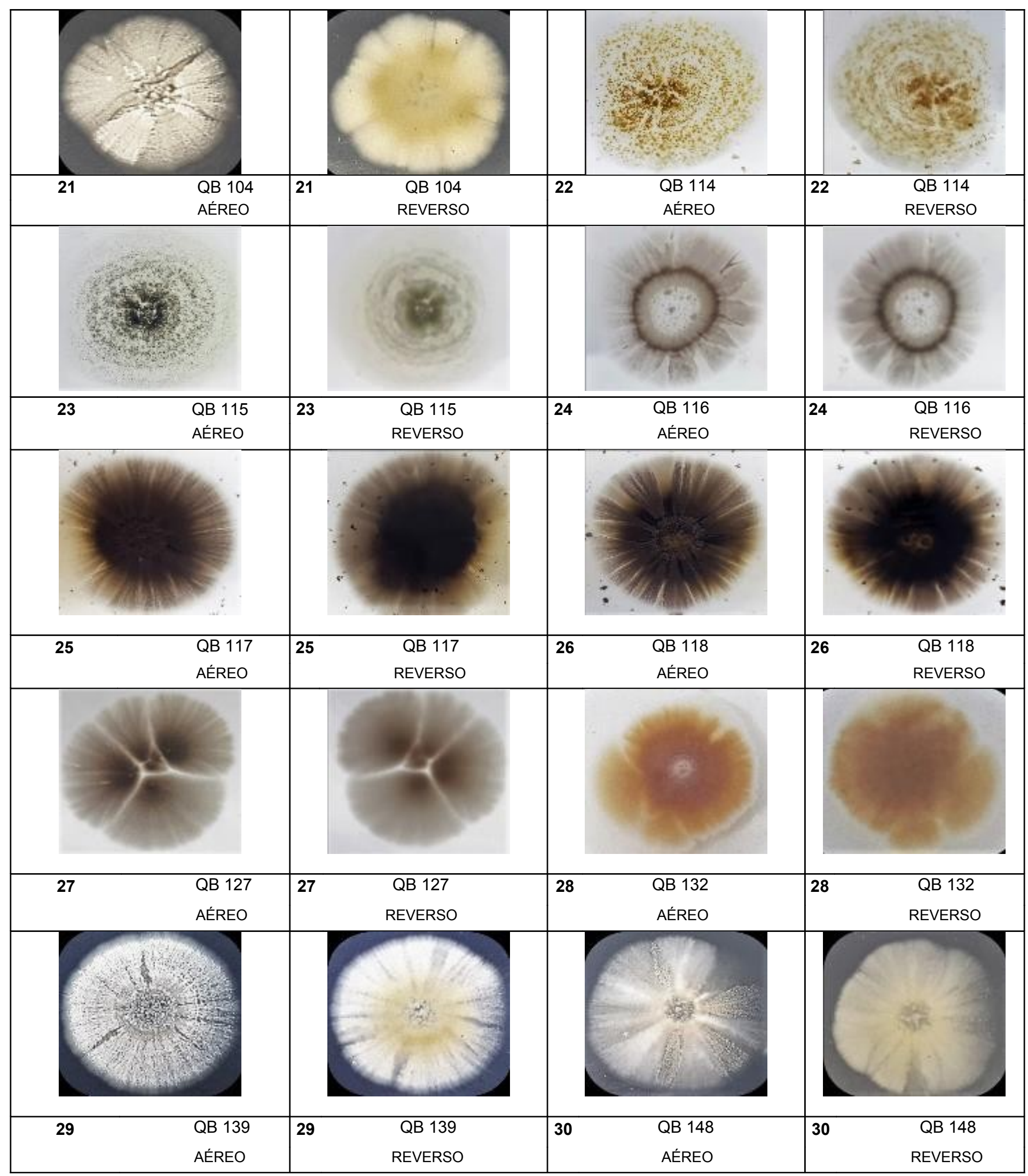




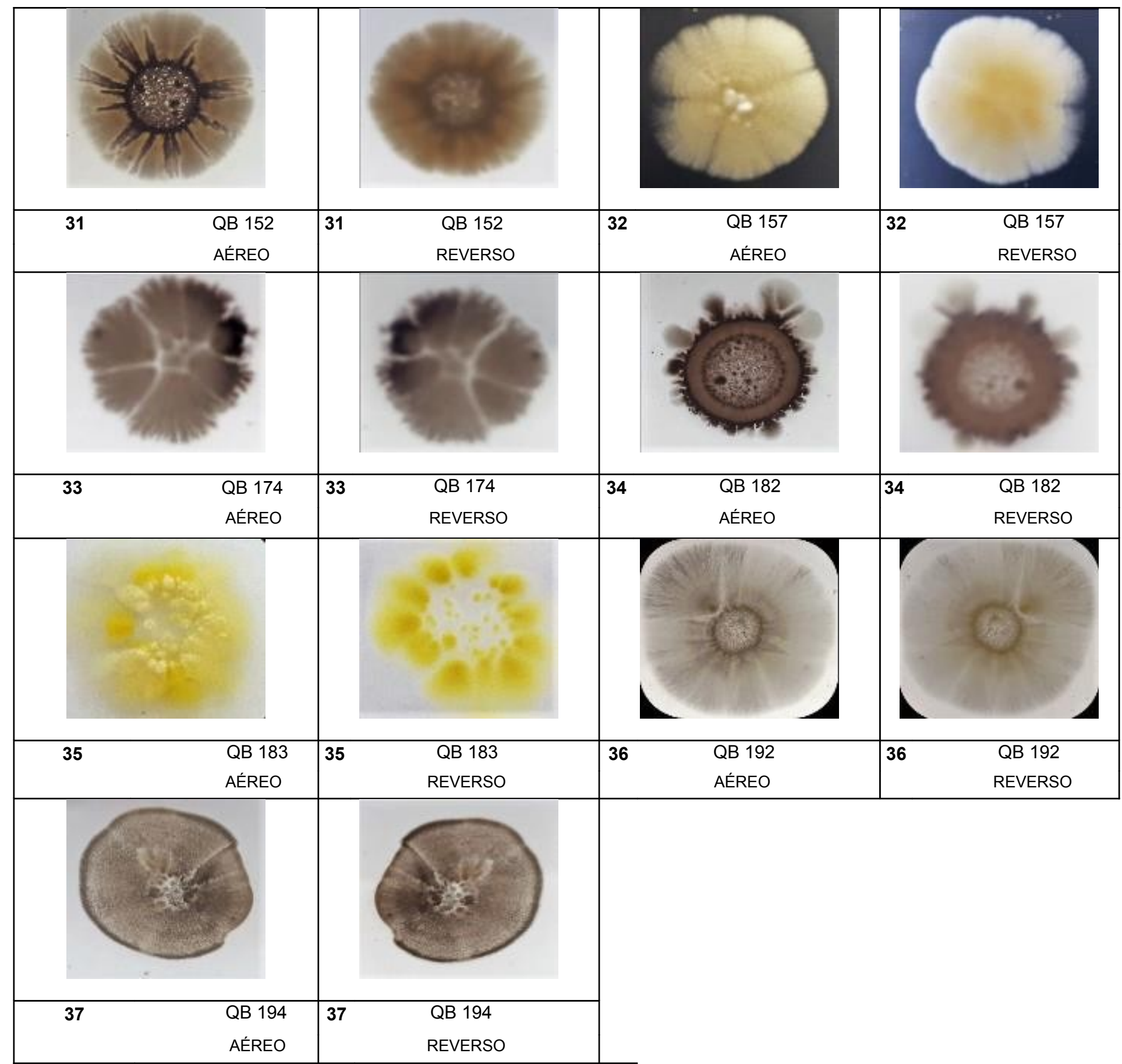

Figura 3: Diversidade cultural das cepas de actinobactérias oriundas de Quixeramobim (Ce) em colônias isoladas.

A observação do micélio aéreo e o reverso demonstrou que $80 \%$ das cepas apresentaram semelhança. Entretanto, nas cepas QB 12, QB 39, QB 72, QB 76, QB 81, QB 93, QB 99 e QB 100, o micélio reverso apresentava uma coloração distinta do micélio aéreo.

Houve diferença entre as cepas quanto a cor dos micélios, demonstrando a diversidade cultural desse grupo. Sabe-se, que a produção de pigmentos não é imprescindível para o crescimento microbiano, mas tem-se o conhecimento de que exerce importante papel ecológico, contribuindo para a sobrevivência e competitividade dos micro-organismos (SHARMA, 2014; OLIVEIRA et al., 2014). Essa diversidade microbiana no solo é de extrema importância, visto que, a ENCICLOPÉDIA BIOSFERA, Centro Científico Conhecer - Goiânia, v.15 n.27; p. 2142018 
diminuição da diversidade, pode resultar em decréscimo na atividade de ciclagem de nutrientes e crescimento vegetal (REBER, 1992).

No total, trinta cores distintas foram constatadas, demonstrando assim, a vasta diversidade das actinobactérias na região semiárida (Figura 4).

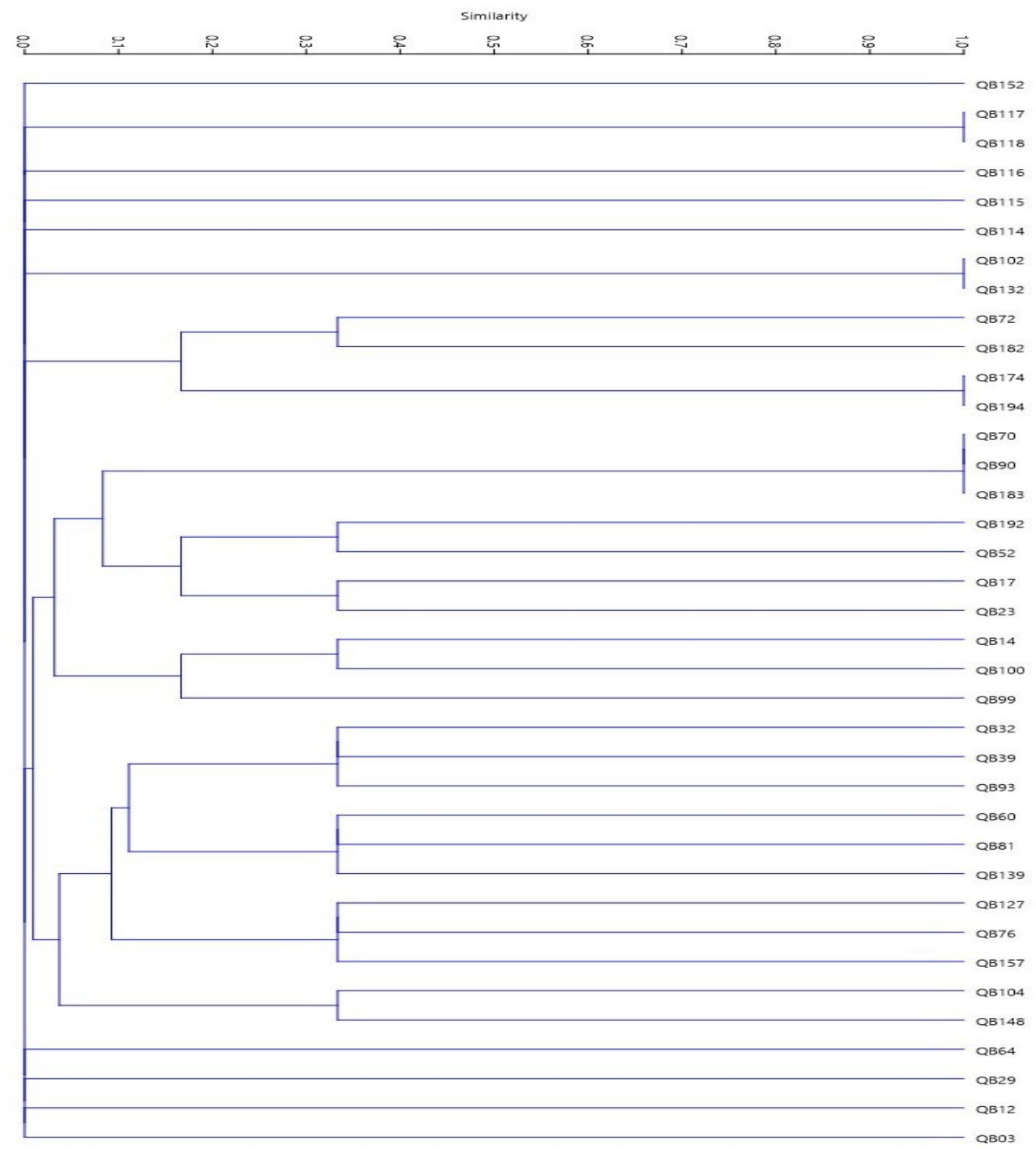

Figura 4: Dendrograma de similaridade do micélio aéreo e reverso das actinobactérias oriundas de Quixeramobim (Ce).

A produção de pigmentos por actinobactérias é um bom critério para estudos taxonômicos. Estes pigmentos são descritos em tons de azul, violeta, vermelho, rosa, amarelo, verde, marrom e preto, que podem estar dissolvidos no meio ou retidos no micélio (AMAL et al., 2011).

Dentre as cepas analisadas, cerca de $19 \%$ apresentaram pigmento difusivo. Neste estudo, as cores marrom e amarela foram predominantes em comparação com as constatadas por Ramos et al. (2015) e Silva et al. (2015), que, ao descreverem culturalmente cepas de actinobactérias, também provenientes do semiárido, observaram a predominância das cores cinza, creme e branco. 
Tendo em vista que a comunidade edáfica do semiárido, ainda necessita de muitos estudos, é bem possível que a diversidade seja superior ao que se tem conhecimento.

\section{CONCLUSÃO}

Pode-se observar diversidade quanto ao aspecto cultural entre as cepas de actinobactérias, e essa diferença foi documentada por meio de registro fotográfico. Dessa forma, o material gerado poderá ser utilizado como material de consulta na caraterização de novas cepas oriundas do semiárido.

\section{REFERÊNCIAS}

AMAL, A. M.; ABEER, K. A.; SAMIA, H. M.; ABD EL-NASSER H. N.; AHMED, K. A.; EL-HENNAWI, H. M. Selection of pigment (melanin) production in Streptomyces and their application in printing and dyeing of wool fabrics. Research Journal of Chemical Sciences. v.1, n.5, p. 22-28, 2011. Disponível em: https://www.semanticscholar.org/paper/Selection-of-Pigment-(Melanin)-production-inand-in-Amal-Abeer/4e0ce8e436cd94b5bf04ac19145f9ddbff5a850f

BALLAV, S.; DASTAGER, S. G.; KERKAR, S. Biotechnological significance of Actinobacterial research in India. Recent Research in Science and Technology, v.4, n.4, $\quad$ p. 31-39, 2012 . Disponível em: https://pdfs.semanticscholar.org/85e4/a1ef94d792f95cffe0587b34cbdcfee2b521.pdf

BARKA, E. A.; VATSA, P.; SANCHEZ, L.; GAVEAU-VAILLANTA, N.; JACQUARD, C. et al. Taxonomy, physiology, and natural products of Actinobacteria. Microbiology and Molecular Biology Reviews, [s.I.], v. 80, n. 1, p.1-43, 2015. Disponível em: http://dx.doi.org/10.1128/MMBR.00019-15 >. doi:10.1128/MMBR.00019-15

BHASIN, S; CAMEOTRA, S; MODI, H. Actinomycetal diversity of western region of Madhya Pradesh. Journal of Advances in Developmental Research, v.1, n. 2, p.132-138, 2010. Disponível em: https://www.researchgate.net/publication/267716043_Actinomycetal_Diversity_of_W estern_Region_of_Madhya_Pradesh

BRITO, F. A. E.; RAMOS, K. A.; DA SILVA, R. M. ; MARTINS, C. M.; MARTINS, S. C. S. Actinobacteria from rizospheric soil in the caatinga biome. Enciclopédia $\begin{array}{lllll}\text { Biosfera, } & \text { v. } & 11, & \text { p. } & 1992-2004,\end{array}$ http://www.conhecer.org.br/enciclop/2015b/biologicas/actinobacterias.pdf

GORLACH-LIRA, K., COUTINHO, H. D. M. Population dynamics and extracelular enzymes activity of mesophilic and thermophilic bacteria isolated from semi-arid soil of Northeastern Brazil. Brazilian Journal of Microbiology, v.38, p. 135-141, 2007. Disponível em: <http://dx.doi.org/10.1590/S1517-83822007000100028>. doi: 10.1590/S1517-83822007000100028

IPECE-INSTITUTO DE PESQUISA E ESTRATÉGIA ECONÔMICA DO CEARÁ. 2014. Perfil básico municipal 2014-Quixeramobim. Disponível em: <http://www.ipece.ce.gov.br/perfil_basico_municipal/2014/Quixeramobim.pdf>. Acesso: 20 nov 2017.

KAVAMURA, V. N.; TAKETANI, R. G.; LANÇONI, M. D.; ANDREOTE, F. D.; MENDES, R.; MELO, I. S. Water regime influences bulk soil and rhizosphere of Cereus jamacaru bacterial communities in the Brazilian Caatinga biome. PloS one, ENCICLOPÉDIA BIOSFERA, Centro Científico Conhecer - Goiânia, v.15 n.27; p. 216 2018 
v.8, n.9, p.e73606, 2013. Disponível em: <https://doi.org/10.1371/journal.pone.0073606>. doi:10.1371/journal.pone.0073606

LI, Q.; CHEN, X.; JIANG, Y.; CHENGLIN, J. Morphological Identification of Actinobacteria. Actinobacteria - Basics and Biotechnological Applications, [s.I.], p.59-86, 2016. Disponível em: <https://doi.org/10.5772/61461 > doi: 10.5772/61461.

LIMA, J. V. L., PINHEIRO, M. S., FIÚZA, L. M. C. G., MARTINS, S. C. S., MARTINS, C. M. Populações microbianas cultiváveis do solo e serrapilheira de uma unidade de conservação no semiárido brasileiro. Enciclopédia Biosfera, v.10, p. 2300-2316, 2014.

Disponível

em:

http://www.conhecer.org.br/enciclop/2014a/AGRARIAS/populacoes.pdf

MOREIRA, F., SIQUEIRA, J. Microbiologia e Bioquímica do Solo. $2^{a}$ Ed. Atual ampliada. Minas Gerais: Universidade Federal de Lavras (UFLA), Brazil, 2006; p.729.

OLIVEIRA, A. P. G.; SABINO, S. M.; GANDINE, S. M.; MOULIN, T.; AMARAL, A. A. Importância das actinobactérias em processos ecológicos, industriais e econômicos. Enciclopédia Biosfera, v.10, n.18; p. 3938-3952, 2014. Disponível em: http://www.conhecer.org.br/enciclop/2014a/MULTIDISCIPLINAR/importancia.pdf

PRIYADHARSINI, P; DHANASEKARAN, D. Diversity of soil Allelopathic Actinobacteria in Tiruchirappalli district, Tamilnadu, India. Journal of The Saudi Society of Agricultural Sciences, [s.I.], v. 14, n. 1, p.54-60, 2015. Disponível em: <https://doi.org/10.1016/j.jssas.2013.07.001>. doi:10.1016/j.jssas.2013.07.001.

RAMOS, K. A.; BRITO, F. A. E.; NUNES, K. J. F.; MARTINS, C. M.; MARTINS, S. C. S. Caracterização e diversidade cromogênica de actinobactérias de um nicho microbiano preservado do bioma caatinga. Enciclopédia Biosfera, v. 11, p.21152125, 2015. Disponível em: < http://www.conhecer.org.br/enciclop/2015b/biologicas/caracterizacao\%20e \%20diversidade.pdf

REBER, H.H. Simultaneous estimates of the diversity and the degradative capability of heavy-metal-affected soil bacterial communities. Biology and Fertility of Soils, v.13, p.181-186, 1992. Disponível em: < https://doi.org/10.1007/BF00336277>. doi:10.1007/BF00336277.

SEMÊDO, L. T. A. S, LINHARES, A. A, GOMES, R. C, MANFIO, G. P, ALVIANO, C.S, LINHARES, L. F, COELHO, R. R. Isolation and caracterization of actinomycetes from Brazilian tropical soils. Microbiological Research, v.155, p. 291-299, 2001. Disponível em: < https://doi.org/10.1016/S0944-5013(01)80007-0>. doi:10.1016/S0944-5013(01)80007-0.

SERVIN, J. A.; HERBOLD, C.W.; SKOPHAMMER, R. G.; LAKE J.A. Evidence excluding the root of the tree of life from the actinobacteria. Molecular Biology and Evolution, [s.l.], $\quad$ v. $25, \quad$ n. 1 , p.1-4, 2008. Disponível em: < https://doi.org/10.1093/molbev/msm249>. doi:10.1093/molbev/msm249.

SHARMA, M. Actinomycetes: Source, identification, and their applications. International Journal of Current Microbiology and Applied Science. v.3, n.2, p. 801-832, 2014. Disponível em: < https://www.researchgate.net/publication/292100429_Actinomycetes_Source_identifi cation_and_their_applications 
SILVA, M. S.; SALES, A. N.; MAGALHÃES-GUEDES, K. T.; DIAS, D. R.; SCHWAN, R. F. Brazilian Cerrado Soil Actinobacteria Ecology. BioMed Research International, v. 2013, p. 1-10, 2013. Disponível em: $<$ http://dx.doi.org/10.1155/2013/503805>.

SILVA, V. M. A.; LIMA, J. V. L; GONDIM, P. M..; MARTINS, C. M; SUZANA, C. S. M. Effect of irrigation and type of cultivation on richness and diversity of chromogenic actinobacteria of soil from Ceará semiarid region. Enciclopédia Biosfera, v. 11, p. 2965-2979, 2015.

Disponível em:

https://www.researchgate.net/publication/316278948_Characterization_of_actinobact eria_from_the_semiarid_region_and_their_antagonistic_effect_on_strains_of_rhizobi a

STROBEL, G.; DAISY, B.; CASTILLO, U; HARPER, J. Natural products from endophytic microorganisms. Journal of Natural Products, [s.l.], v. 67, n. 2, p.257268, 2004. Disponível em: <https://doi.org/10.1021/np030397v>. doi:10.1021/np030397v.

WINK, J. M. Compendium of actinobacteria. University of Braunschweig. p. 1-37, 2012.

ZANELLA, M. E. Considerations on climate and water resources of the Northeastern semiarid. Caderno Prudentino de Geografia, n. 36, p. 126-142, 2014. Disponível em: revista.fct.unesp.br/index.php/cpg/article/download/3176/2680 